\title{
Method for Isolating Auxotrophic Mutants in Aspergillus nidulans Using $N$-glycosyl-polifungin
}

\author{
By J. BAL, E. BALBIN AND N. J. PIENIĄŻEK \\ Department of Genetics, Warsaw University, Al. Ujazdowskie 4, \\ 00-478 Warsaw, Poland
}

(Received 3I January 1974; revised 5 April 1974)

\begin{abstract}
SUMMARY
A method for the selection of auxotrophic mutants in Aspergillus nidulans using $N$-glycosyl-polifungin has been developed. The method results in about 9000fold enrichment. All types of auxotrophs were obtained. Under certain conditions preferential selection of nucleic acid hydrolysate-requiring auxotrophs was observed. The frequency of occurrence of these mutants was about $50 \%$ of all colonies tested. Cysteine auxotrophs of $A$. nidulans were obtained for the first time by means of this method.
\end{abstract}

\section{INTRODUCTION}

There are many methods of selecting auxotrophic mutants. The penicillin method is effective and widely used for bacteria (Davis, 1948; Lederberg \& Zinder, 1948). No such universal technique is available for fungi. In 1959 Moat, Peters \& Srb made the first attempts to use the antifungal effects of polyene antibiotics for selection of auxotrophic mutants in yeast. Polyene antibiotics form complexes with the sterols of cell walls (Lampen, Arnow, Borowska \& Laskin, 1962; Norman et al. 1972) causing considerable changes in permeability (Lampen et al. 1962; Stachiewicz \& Quostel, I963; Kinsky, Luse \& van Deenen, 1966). It has also been suggested that polyenes have an effect on the general conformation of the cell wall (Chuen-Chin \& Feingold, 1973). The selective action of polyene antibiotics is especially strong during increased metabolic activity of the cell (Snow, I966). This allows their application as agents for selecting auxotrophs.

Polyene antibiotics yielded positive results when used for selection of auxotrophic mutants in yeast (Snow, I966; Thouvenot \& Bourgeois, 197I) when a method similar to the penicillin method was applied. In the selection of auxotrophic mutants in bacteria and yeast the cells after mutagenesis were placed in complete liquid medium to allow the phenotypic expression of the induced mutations and were subsequently transferred to selective medium. On this medium the cells were exposed to the antibiotic. In the case of filamentous fungi, the time of the incubation in liquid medium is strictly limited because they form a mycelium, so the method described above is inadequate for these organisms. The attempts which were made hitherto to bypass this difficulty (Ditchburn \& MacDonald, I97I) were not completely satisfactory, see Discussion.

In this paper a method for isolating auxotrophic mutants in $A$, nidulans using $N$-glycosylpolifungin as the selective agent is described. This agent is a derivative of polifungin (Kotiuszko, Wituch, Morawska \& Siejko, I97I). N-glycosyl-polifungin has been synthesized by Professor Borowski. It is at present the only water-soluble polyene antibiotic - a property that makes it more convenient to use. 


\section{METHODS}

Strains. In this work the strains mecAI, biAI; pabaA2,biAI and $y, b i A I, \arg A I$ from the Department of Genetics of the University of Warsaw were used. The symbols represent appropriate nutrient requirements, mec representing the inability to catabolize methionine (Pieniążek, Stępień \& Paszewski, 1973) which does not lead to auxotrophy.

The genetic analysis was performed by inoculating 26 colonies per plate with complete medium; after incubation they were replicated using a replicator with 26 steel needles on selective media.

Media. All media as well as nutrient supplements necessary for growth were standard (Pontecorvo et al. 1953).

Chemicals. The tris salt of $\mathrm{N}$-glycosyl-polifungin (NGP) obtained at the Department of Drug Technology and Biochemistry of the Gdańsk Institute of Technology, Poland (Patent Application PI49994: Method for obtaining derivatives of the macrolide polyene antibiotic; L. Falkowski, J. Pawlak, E. Bylec, J. Golik, P. Kołodziejczyk, T. Zieliński, A. Rudkowski \& E. Borowski, I97I) was used. Three different samples from the experimental production with activites of I I00, 960 and $\mathrm{I} 300$ units $/ \mathrm{mg}$ respectively were used. The activity of the preparations was determined by the cylinder flat method in Saccharomyces cerevisiae ATCC9763 against a standard of insoluble polifungin (POLFA).

The antibiotic was stored at $-10{ }^{\circ} \mathrm{C}$. Solutions were prepared immediately before use by dissolving NGP in liquid medium to the required final concentration. The solutions were not sterilized before use.

The choice of NGP as the most effective antibiotic was made on the basis of comparisons between mycostatin (SQUIBB), nystatin (POLFA), insoluble polifungin (POLFA) and NGP (unpublished data).

\section{RESULTS}

\section{Determination of the optimal time of action and concentration of NGP}

As the polyene antibiotics are most effective during germination of the conidia, the time of germination was determined in the $m e c A I$, biAI strain. In biotin-supplemented minimal medium conidia of this strain germinate between the fourth and sixth hour of incubation. Therefore the antibiotic in subsequent experiments was added $4.5 \mathrm{~h}$ after starting the incubation in experiments in which $\mathrm{I} h$ incubation with the antibiotic was applied, and $3 \mathrm{~h}$ after starting the incubation in experiments in which $3 \mathrm{~h}$ incubation with the antibiotic was applied.

It was necessary to determine an antibiotic treatment in which the survival of auxotrophs was high and the survival of prototrophs very low. The method proposed by Moat et al. (I959) was used. The sensitivities of strains $m e c A I, b i A I$ and $y, b i A I, \arg A I$ to various concentrations of the antibiotic were compared. On biotin-supplemented minimal medium the former strain behaves as a prototroph while the later is an arginine auxotroph. The ratio of survival of the auxotroph to that of the prototroph at a given antibiotic concentration was a measure of the effectiveness of the NGP. This value, described as the enrichment factor, equals $I$ in the control sample. The antibiotic concentrations used were 50, 100, 200, 500 and 1000 units $/ \mathrm{ml}$. The experiments were performed using both $\mathrm{I}$ and $3 \mathrm{~h}$ incubation with the antibiotic.

The analysis of the results obtained indicates that NGP is very effective (Fig. I). The sensitivity of the prototroph is much greater than that of the auxotroph. The enrichment factors were $\mathrm{I} 658$ and 8882 for $\mathrm{I}$ and $3 \mathrm{~h}$ incubation with the antibiotic respectively. Both values were obtained when the final concentration of NGP was 500 units $/ \mathrm{ml}$. 

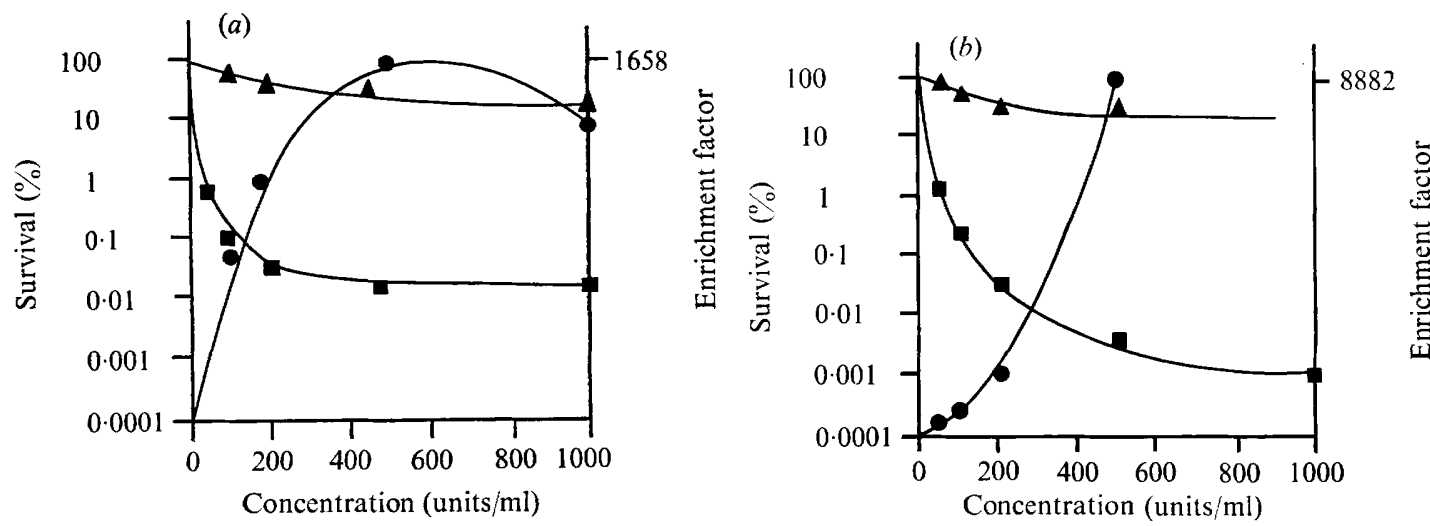

Fig. I. The effect of different concentrations of NGP for $(a) \mathrm{I} \mathrm{h},(b) 3 \mathrm{~h}$, on the survival of conidia of $m e c A I, b i A I$ and $y, b i A I, \arg A I$ strains of Apsergillus nidulans in biotin-containing minimal medium. $\boldsymbol{\square}, \operatorname{mec} A I, b i A I ; \boldsymbol{\Lambda}, y, b i A I, \arg A I ; \boldsymbol{\ominus}$, enrichment factor.

\section{The action of the NGP in the selection of new mutants}

Induction of mutants. The mutations were induced by irradiating a conidial suspension with u.v. (254 nm wavelength). An u.v. CAMAG (Switzerland) lamp was used. Survival of the conidia was in the range 0.5 to $2 \%$.

Phenotypic expression of induced mutations. Snow (1966) showed that selection for auxotrophs immediately after mutagenesis did not yield positive results. Induced mutations were not expressed phenotypically. To determine if this were also true for u.v.-induced mutations in $A$. nidulans, the number of auxotrophic mutants in a sample of u.v.-irradiated conidia and a sample exposed to NGP after mutagenesis were compared. The NGP was added after $4.5 \mathrm{~h}$ incubation in liquid minimal medium supplemented with biotin. Conidia were incubated for I $h$ with NGP at a final concentration of Ioo units $/ \mathrm{ml}$. In both experiments the frequency of auxotrophic mutants was about $0 . \mathrm{I} \%$. In subsequent experiments the conidia after mutagenesis were plated on solid medium to allow the phenotypic expression of the mutations.

Selection of the mutants. Ultra-violet-irradiated condidia from the mecAI, biAI strain were plated on to complete solid medium. After 3 days' incubation the conidia were collected into water containing Tween 20 (0.1 \% solution) and centrifuged to remove the remains of the solid medium. Biotin-supplemented liquid minimal medium was inoculated with these conidia. The density of this suspension never exceeded $10^{7}$ conidia $/ \mathrm{ml}$. The suspension was incubated in an orbital shaker at $34^{\circ} \mathrm{C}$. After the appropriate time the solution of the antibiotic was added. Both $\mathrm{I}$ and $3 \mathrm{~h}$ incubation with the NGP were used. Conidia were separated from the antibiotic by centrifugation and plated on complete solid medium. The number and type of mutants in samples of conidia subjected to various concentrations of NGP were examined (see Methods). A considerable increase in the number of mutants was observed as compared with the untreated sample (Table I). All kinds of mutants were obtained. The greatest enrichment was observed after $3 \mathrm{~h}$ incubation with the antibiotic at 200 units $/ \mathrm{ml}$. At higher concentrations smaller numbers of auxotrophs were obtained. A similar dependence was observed for $\mathrm{I} h$ incubation with NGP, though the number of mutants was smaller and the maximal enrichment was given by a concentration of 500 units $/ \mathrm{ml}$ (Table I).

Preferential selection of nucleic acid hydrolysate auxotrophs. In all experiments the 
Table I. Comparison of frequency and types of auxotrophs of Aspergillus nidulans mecAI, biAI with respect to the time of action and concentration of NGP

\begin{tabular}{|c|c|c|c|c|c|c|c|c|}
\hline \multirow{3}{*}{$\begin{array}{l}\text { Time of } \\
\text { NGP } \\
\text { action } \\
\text { (h) }\end{array}$} & \multirow{3}{*}{$\begin{array}{c}\text { Concn } \\
\text { of NGP } \\
\text { (units/ml) }\end{array}$} & \multirow{3}{*}{$\begin{array}{l}\text { No. } \\
\text { colonies } \\
\text { tested }\end{array}$} & \multicolumn{5}{|c|}{ Auxotrophs } & \multirow{3}{*}{$\begin{array}{l}\text { Enrichment } \\
\text { factor }\end{array}$} \\
\hline & & & \multirow[b]{2}{*}{ No. } & \multirow[b]{2}{*}{ Percentage } & \multicolumn{3}{|c|}{ Type* } & \\
\hline & & & & & A & V & $\mathbf{N}$ & \\
\hline - & 一 & 2500 & I & 0.04 & - & I & - & I.O \\
\hline \multirow[t]{4}{*}{ I } & 50 & $\begin{array}{l}308 \\
382\end{array}$ & 5 & $\begin{array}{l}1 \cdot 60 \\
2 \cdot 40\end{array}$ & $\bar{I}$ & I & 4 & $\begin{array}{l}40 \cdot 0 \\
60 \cdot 0\end{array}$ \\
\hline & 200 & 389 & II & 2.80 & 2 & 2 & 7 & $70 \cdot 0$ \\
\hline & 500 & 388 & 35 & $9 \cdot 00$ & I & 8 & 26 & $225 \cdot 3$ \\
\hline & 1000 & $3 I I$ & 14 & $4 \cdot 20$ & 1 & 3 & 10 & $112 \cdot 5$ \\
\hline \multirow[t]{4}{*}{3} & 50 & 115 & 4 & 3.50 & I & - & 3 & 87.5 \\
\hline & 100 & 182 & 19 & $10 \cdot 40$ & 一 & 2 & 17 & $260 \cdot 0$ \\
\hline & 200 & 323 & 52 & $16 \cdot 10$ & 4 & 4 & 46 & $402 \cdot 5$ \\
\hline & 500 & 228 & 23 & $10 \cdot 10$ & 2 & I & 20 & 252.5 \\
\hline
\end{tabular}

* A, amino acid auxotrophs; V, vitamin auxotrophs; N, nucleic acid hydrolysate-requiring auxotrophs.

majority of the mutants required a hydrolysate of nucleic acids for growth. The proportion of nucleic acid hydrolysate requiring auxotrophs was dependent on the degree of antibiotic treatment (Table I). Experiments were performed to determine whether this were a property of the mecAI, biAI strain. Conidia of the pabaAz, biAI strain after mutagenesis and phenotypic expression of mutations were incubated in minimal liquid medium supplemented with biotin and $p$-aminobenzoic acid and treated with NGP at 100 units $/ \mathrm{ml}$ for $\mathrm{I} h$. Among I6 auxotrophs, I5 required nucleic acid hydrolysate for growth (Table 2).

\section{Selection of specific mutant classes}

Obtaining specified classes of mutants. The preferential selection of nucleic acid hydrolysate-requiring auxotrophs does not exclude the possibility of obtaining other types of mutants. If conidia after mutagenesis are plated on medium lacking hydrolysate of nucleic acids all nucleic acid hydrolysate-requiring auxotrophs will be eliminated. To isolate amino acid-requiring mutants in the mecAI, biAI and pabaA2, biAI strains the conidia after mutagenesis were plated on minimal medium supplemented with biotin, or biotin and $p$-aminobenzoic acid, and casein hydrolysate. To isolate vitamin auxotrophs, conidia were plated on minimal medium supplemented with vitamins. In both cases (Table 2) more mutants were obtained than by total isolation. When conidia after mutagenesis were plated on minimal medium with a hydrolysate of nucleic acid and appropriate vitamins, $62.5 \%$ of nucleic acid hydrolysate-requiring auxotrophs were obtained in the mecAI, biAI strain and $25.7 \%$ in the paba2, biAI strain (Table 2), which confirms the preferential selection of this class of mutants. The lower number of auxotrophs in the pabaAz, biAI strain than in the mecAI, biAI strain could be due to differences of composition of sterols in the cell wall (see Introduction).

It is possible to repeat the NGP treatment before mutant isolation. In an experiment with the mecI, biAI strain the percentage of mutants was lower after the second than after the first incubation with NGP. This was probably due to the more efficient formation of conidia by prototrophs than by auxotrophs.

Obtaining cysteine auxotrophs. An attempt was made to obtain cysteine auxotrophs since these mutants had not been obtained by velvet replication even though approximately 50000 colonies had been screened. The mutations were induced in the mecAI, biAI strain 
Table 2. Comparison of the frequency and types of auxotrophs of mecAI, biAI and pabaA2, biAI strains of Aspergillus nidulans obtained by total isolation and the polifungin method

\begin{tabular}{|c|c|c|c|c|c|c|c|c|}
\hline \multirow{3}{*}{$\begin{array}{l}\text { Isolation } \\
\text { method }\end{array}$} & \multirow[b]{3}{*}{ Strain } & \multirow{3}{*}{$\begin{array}{l}\text { Medium on which } \\
\text { conidia were plated } \\
\text { after mutagenesis }\end{array}$} & \multirow{3}{*}{$\begin{array}{l}\text { No. } \\
\text { colonies } \\
\text { tested }\end{array}$} & \multicolumn{5}{|c|}{ Auxotrophs } \\
\hline & & & & \multirow[b]{2}{*}{ No. } & \multirow{2}{*}{$\begin{array}{l}\text { Per- } \\
\text { centage }\end{array}$} & \multicolumn{3}{|c|}{ Type* } \\
\hline & & & & & & A & V & $\mathbf{N}$ \\
\hline \multirow{2}{*}{$\begin{array}{l}\text { Total } \\
\text { isolation }\end{array}$} & \multirow{2}{*}{$\begin{array}{l}\operatorname{mec} A I, b i A I \\
\text { pabaA2,biAI }\end{array}$} & \multirow[t]{2}{*}{$\mathrm{CM}$} & 2500 & I & 0.04 & - & I & 一 \\
\hline & & & 1040 & $\mathbf{I}$ & 0.10 & 一 & I & 一 \\
\hline \multirow{8}{*}{$\begin{array}{l}\text { Polifungin } \\
\text { method }\end{array}$} & \multirow{4}{*}{$\begin{array}{l}\text { mecAI, biAI } \\
\text { pabaA2, biAI } \\
\text { mecAI, biAI } \\
\text { pabaA2, biAI }\end{array}$} & \multirow[t]{2}{*}{$\mathrm{CM}$} & 274 & 122 & $44 \cdot 50$ & 2 & - & I 20 \\
\hline & & & $5 \mathrm{I} 6$ & 16 & $3 \cdot 10$ & - & I & I 5 \\
\hline & & $\mathbf{M M}+\mathrm{bi}+$ amino acids & 277 & I5 & $5 \cdot 40$ & 15 & - & - \\
\hline & & $\begin{array}{l}\mathrm{MM}+\mathrm{bi}+\text { paba }+ \text { amino } \\
\text { acids }\end{array}$ & $45^{8}$ & 8 & $1 \cdot 70$ & 8 & 一 & 一 \\
\hline & $\operatorname{mec} A I, b i A I$ & $\mathbf{M M}+$ vitamins & 234 & 23 & $9 \cdot 80$ & 一 & 23 & - \\
\hline & $p a b a A 2, b i A I$ & & 494 & 6 & $\mathrm{I} \cdot 20$ & - & 6 & - \\
\hline & mecAI, biAI & $\mathrm{MM}+\mathrm{bi}+$ nucleic acids & 260 & 162 & $62 \cdot 30$ & - & - & 162 \\
\hline & $p a b a A 2, b i A I$ & $\begin{array}{l}\mathrm{MM}+\mathrm{bi}+\text { paba }+ \text { nucleic } \\
\text { acids }\end{array}$ & 494 & 127 & 25.40 & - & 一 & I 27 \\
\hline
\end{tabular}

in which methionine catabolism is blocked (Pieniążek et al. 1973). After mutagenesis the conidia were plated on minimal medium supplemented with biotin and cysteine. The conidia were harvested and inoculated onto biotin-supplemented liquid minimal medium and incubated for $4.5 \mathrm{~h}$. Subsequently NGP ( 100 units $/ \mathrm{ml}$ ) was added for I h. After incubation, the antibiotic was removed and the conidia plated on minimal medium supplemented with biotin and cysteine. Colonies obtained on this medium were inoculated in the same medium (26 colonies/plate) and replicated on to minimal medium with biotin. In four independent experiments 2073 colonies altogether were screened and I 3 cysteine auxotrophs obtained. It is possible that most of these mutants are members of a clone; this has not been further investigated. A detailed biochemical study of cysteine auxotrophs has been made by N. J. Pieniążek, J. Bal, E. Balbin \& P. P. Stępień (I 974).

\section{DISCUSSION}

The method of selection of auxotrophic mutants described is not completely analogous to the penicillin method since $A$. nidulans forms a mycelium and therefore cannot be incubated for long in liquid media. However, plating of conidia on solid medium allows the expression of the induced mutations and leads to cloning of mutants. This cloning is especially useful with auxotrophs which occur with very low frequency.

The method described in this paper differs basically from the method proposed for A. nidulans by Ditchburn \& MacDonald (197I). These authors plated conidia after mutagenesis on minimal medium, then poured melted complete medium containing an antibiotic - nystatin - over the plates. They claimed the prototrophs were killed immediately and the antibiotic decomposed before the auxotrophs began to germinate. However, Snow (I966) has shown that exposure to nystatin for several hours also caused non-specific killing of auxotrophs. This has been confirmed in our experiments (unpublished data) in which we used nystatin. In optimal conditions Ditchburn and MacDonald obtained $8.8 \%$ of auxotrophs; we obtained $44.5 \%$, a Iooo-fold enrichment. From the data of Ditchburn and MacDonald it is difficult to estimate the degree of enrichment.

In our investigations on $A$. nidulans using various types of polyenes (unpublished data) 
we observed preferential selection of nucleotide auxotrophs. The preferential selection of nucleic acid hydrolysate-requiring auxotrophs may be because germination of conidia is preceded by replication of DNA. A cell incapable of synthesizing nucleic acids cannot germinate and should be insensitive to NGP.

Cysteine auxotrophs were obtained for the first time using this method, which suggests it may also be effective in the search for other types of auxotrophs.

Of the colonies initially characterized as auxotrophs, $20 \%$ reverted to prototrophy in subsequent tests. These 'revertants' were not taken into consideration in this paper. A similar phenomenon has been observed with both the nystatin and penicillin methods. The reasons are unknown.

Our method of selecting $A$. nidulans auxotrophs is more effective and easier to apply than previously described methods. It should be applicable to other filamentous fungi.

We thank Dr Konstancja Raczyńska-Bojanowska and Dr Danuta Kotiuszko, Institute of Antibiotics, and Dr Leonard Falkowski, Gdańsk Institut of Technology, for providing and assaying the activity of NGP, and are grateful to Dr Ewa Bartnik for advice in the preparation of this paper. This work was supported by the Polish Academy of Sciences within project $09 \cdot 3 \cdot \mathrm{I}$.

\section{REFERENCES}

Chuen-Chin, H. \& Feingold, D. F. (I973). Polyene antibiotic action on leuthin liposomes: effect of cholesterol and fatty acyl chains. Biochemical and Biophysical Research Communications 51, 972-978.

DAvis, B. D. (1948). Isolation of biochemically deficient mutants of bacteria by penicillin. Journal of the Amercan Chemical Society 7o, 4267.

DitchBurn, P. \& MACDonald, K. D. (1971). The differential effects of nystatin on growth of auxotrophic and prototrophic strains of Aspergillus nidulans. Journal of General Microbiology 67, 299-306.

Kinsky, S. C., LUSE, S. A. \& VAN DeEnen, L. L. M. (I966). Interaction of polyene antibiotics with natural and artificial membrane systems. Federation Proceedings 25, 1503-1510.

Kotiuszko, D., Wituch, K., Morawska, H. \& Siejko, D. (I97I). Polifungin, a new antifungal antibiotic. I. Morfological, cultural and physiological properties of Streptomyces sp. strain producing a new complex of tetraene antibiotics. Acta microbiologica polonica 3-4, 135-143.

LAMPEN, J. O., ARnow, P. M., BorowsKa, Z. \& LASKIN, L. (1962). Location and role of sterol at nystatinbinding sites. Journal of Bacteriology 84, $1152-1160$.

LEDERBERG, J. \& ZiNDER, N. (1948). Concentration of biochemical mutants of bacteria with penicillin. Journal of the American Chemical Society 70, 4267.

MoAt, A. G., Peters, N., JUn. \& SRb, A. M. (1959). Selection and isolation of auxotrophic yeast mutants with the aid of antibiotics. Journal of Bacteriology 7, 673-677.

Norman, A. W., Demel, R. A., de Kruyff, B., van Kessel, G. W. S. M. \& van Deenen, L. L. M. (1972). Studies on the biological properties of polyene antibiotics: comparison of the other polyenes with filipin in their ability to interact specifically with sterol. Biochimica et biophysica acta 290, I-I4.

Pienią̇̇ex, N. J., Bal, J., Balbin, E. \& StęPié́, P. P. (1974) Two pathways for cysteine biosynthesis in Aspergillus nidulans. Molecular and General and Genetics (in the press).

Pieniążek, N. J., StȩPień, P. P. \& PASZewski, A. (1973). An Aspergillus nidulans mutant lacking cystathionine $\beta$-synthase: identity of L-serine sulfhydrylase with cystathionine $\beta$-synthase and its distinctness from $O$-acetyl-L-serine sulfhydrylase. Biochimica et biophysica acta 297, 37-47.

Pontecorvo, G., Roper, J. A., Hemmons, L. M., MacDonald, K. D. \& Bufton, A. W. J. (1953). The genetics of Aspergillus nidulans. Advances in Genetics 5, $14 \mathrm{I}-238$.

SNow, R. (1966). Enrichment method for auxotrophic mutants using the antibiotic nystatin. Nature, London 2II, 206-207.

Stachiewicz, E. \& Quostel, J. H. (I963). Amino acid transport in yeast and effect of nystatin. Canadian Journal of Biochemistry and Physiology 4I, 397-407.

Thouvenot, D. R. \& Bourgeors, C. M. (I97I). Optimisation de la sélection de mutants de Saccharomyces cerevisiae par la nystatine. Annales de l'institut Pasteur 120, 617-629. 